\title{
norden
}

Nordic Council of Ministers

Ved Stranden 18

DK-1061 Copenhagen K

www.norden.org

NORDISKE ARBEJDSPAPIRER

NORDIC WORKING PAPERS

\section{Green Economy}

Recent work by the Nordic Council of Ministers

Annegrete Bruvoll

NA2012:904

http://dx.doi.org/10.6027/NA2012-904

This working paper has been published with financial support from the Nordic Council of Ministers. However, the contents of this working paper do not necessarily reflect the views, policies or recommendations of the Nordic Council of Ministers. 



\section{Green Economy: Recent work by the Nordic Council of Ministers}

Annegrete Bruvoll
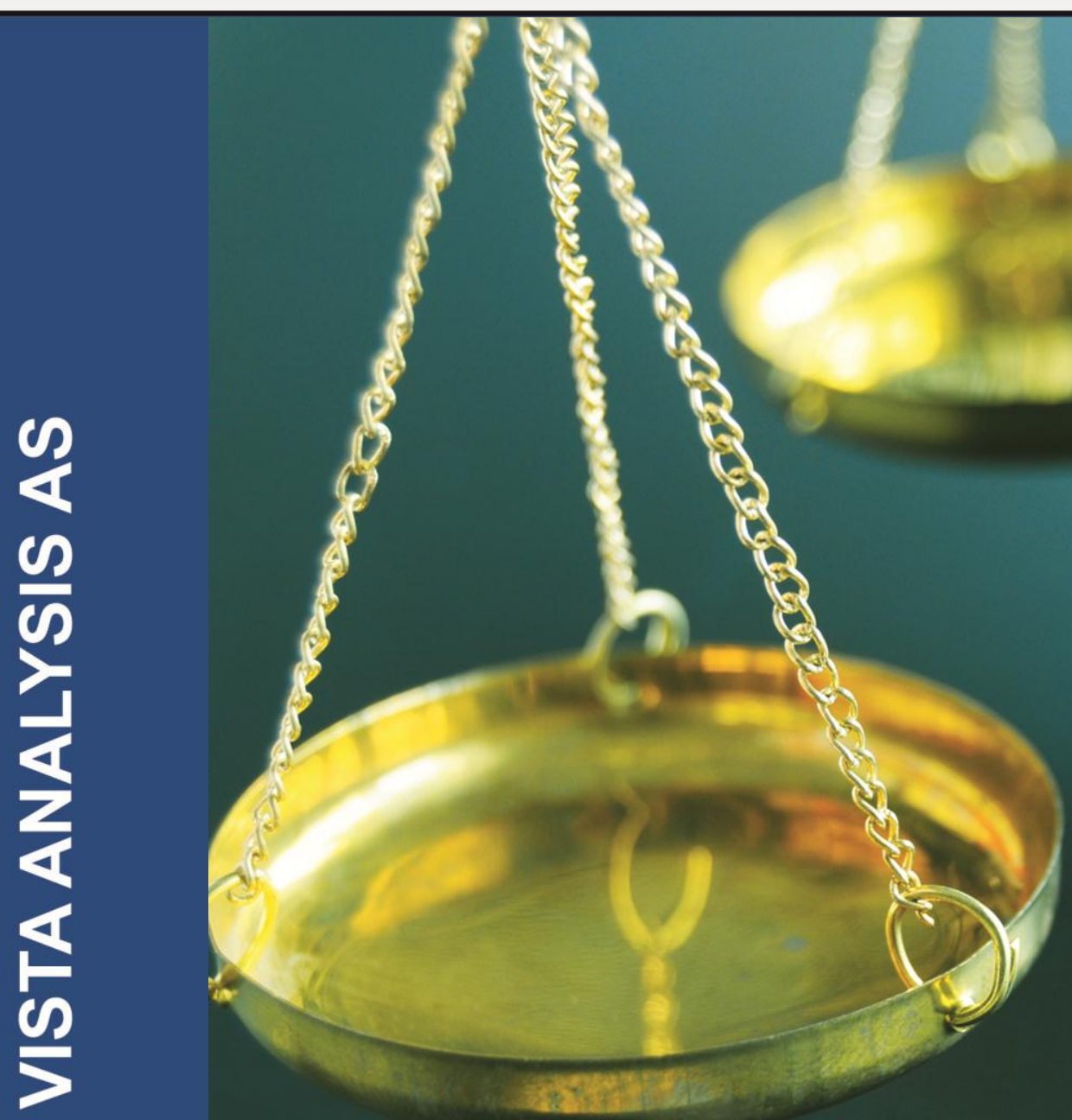



\section{Preface}

The Nordic Council of Ministers has a long tradition for highlighting solutions to the environmental challenges in their working groups, research programs and publications. This reports aim to summarize some of the recent work on greater resource efficiency and greener economic growth and development in the Nordic countries, including core background documents from the Nordic Council of Ministers, The Nordic prime ministers' Working Group for Green Growth, and the EU, research studies related to green growth financed by the Nordic Council of Ministers and the Oslo conference on Green economic growth held in March 2012. The report was commissioned by the Nordic Council of Ministers, with Øyvind Lone, chair of its Working Group on Environment and Economy, as contact person.

26 October 2012

Annegrete Bruvoll

Project leader

Vista Analysis AS 


\section{Content}

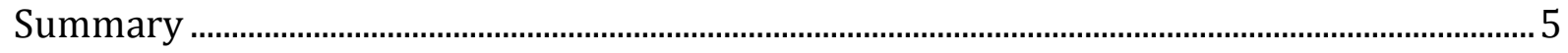

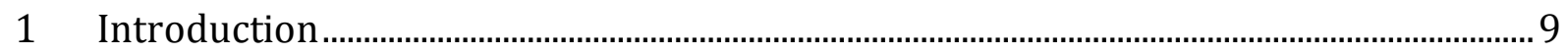

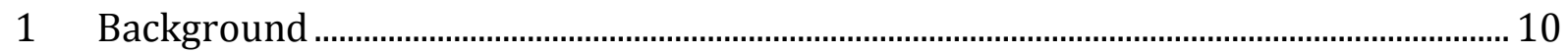

1.1 The environmental action plan 2009-2012 ………………………………………….. 10

1.2 The EU2020 Strategy with its Road Map on resource efficiency ............................ 10

1.3 The Nordic prime ministers' Working Group for Green Growth ............................ 12

2 Projects initiated by the Nordic Council of Ministers ............................................................ 14

2.1 Greening the economy: Nordic experiences and challenges ..................................... 14

2.2 The economic crisis and its consequences.................................................................. 15

2.3 Reforming environmentally harmful subsidies......................................................... 17

2.4 Payment for and management of ecosystem services............................................... 18

2.5 Voluntary agreements and environmental labelling in the Nordic countries ... 19

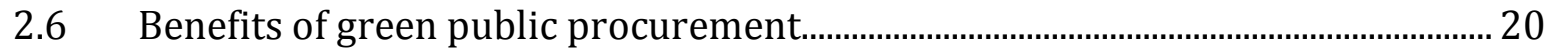

2.7 Valuation of ecosystem services from Nordic watersheds .................................... 21

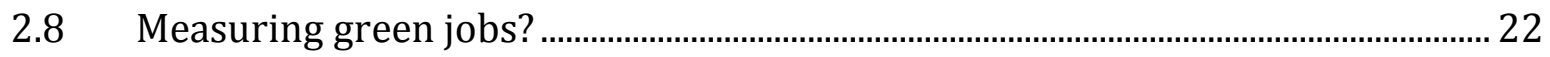

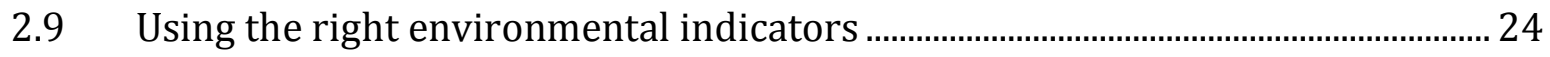

2.10 Environmental technologies in the Nordic countries................................................ 25

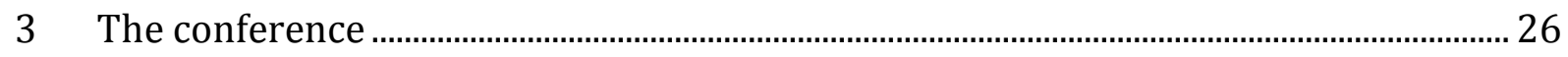

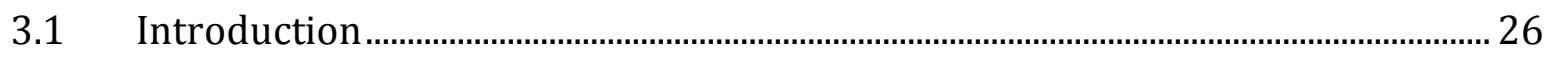

3.2 Session 1: Resources, ecology and growth …………………………………….... 27

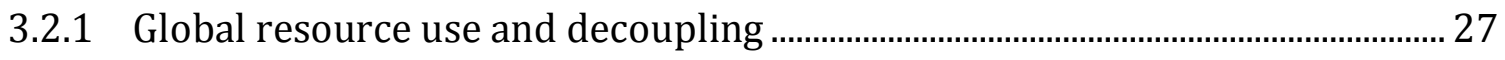

3.2.2 The value of ecosystem services ................................................................................... 28

3.2.3 Europe 2020 and the Roadmap for Resource Efficiency........................................ 29

3.2.4 The Nordic Task Force on Green growth .................................................................... 29

3.3 Session 2: Resource efficiency in industry …………………………………….....2 
3.3.1 Forest industry resource efficiency: Borregaard industries ................................ 30

3.3.2 Resource efficiency and industrial ecology in Kalundborg.................................... 30

3.4 Session 3: Environmental policy, innovation and technology ............................... 30

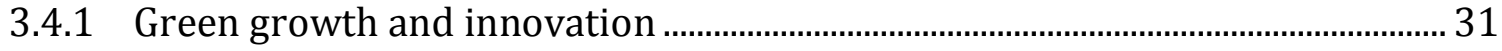

3.4.2 The Nordic Top-level Research Initiative and Green Growth............................... 31

3.4.3 Environmental technology challenges for the Nordic countries......................... 31

3.4.4 Green procurement, labelling and voluntary agreements ................................... 32

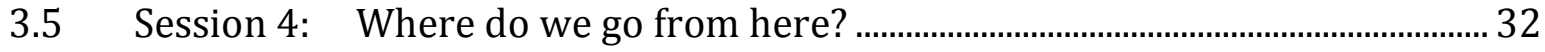

3.5.1 Green growth: China and the Nordic countries .................................................... 32

3.6 Panel debate: Green economic growth in the Nordic countries? ........................... 33

4 Concluding words from the summary conference ........................................................... 34

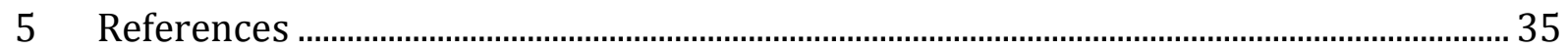




\section{Summary}

The Nordic Council of Ministers has a clear focus on the Nordic countries' role as a pioneer region in the environmental area. The Nordic countries aim to work together in developing expertise and joint strategies on implementation of environmentally friendly policies. The countries have contributed initiatives and tested solutions for international environmental cooperation and exchange of experience, and plan to further enhance cooperation to optimise the utilisation of available resources and find joint solutions in the Nordic region.

The portfolio of reports financed by the Nordic Council of Ministers includes relevant works providing new insight into these areas, in addition to general aspects related to improved efficiency in environmental policy. The synthesis report on Nordic efforts to advance greening of the economy over more than thirty years shows that healthy economic growth can be combined with ambitious and successful environmental goals and policies (section 2.1). Also, studies on decoupling economic growth and growth in emissions to air prove that this has been part of economic historical development (section 3.2.1). This is a natural consequence of general technological progress, but can be stimulated in a more sustainable direction by implementing efficient instruments. However, along with the increasing economic scale, environmental pressure may very well increase despite decoupling. It is hence both a challenge and opportunity for the Nordic countries to improve efficiency in policy design, and to meet new and remaining environmental and economic challenges.

The challenge has been sharpened with the financial crisis from 2007-2008. Economic crises are strong motors for structural changes, which constitute both risks and opportunities. This is studied in section 2.2. It is a particular challenge to balance the environmental and resource concerns with the needs for economic growth. A first order effect of the crisis has been reduced economic growth, with resulting emission reductions. However, environmentally friendly investments risk lower priority in favour of general investments promoting economic growth. The challenge is thus to formulate policies stimulating both economic growth and still taking care of the environment.

The experts contributing at the conference on Green economic growth (chapter 3) generally advised a broad portfolio of instruments. This includes traditional legislative and administrative instruments ("command-and-control"), but generally with a much stronger emphasis on economic and market-based instruments, such as environmental taxes, as well as information instruments (e.g. labelling and certification schemes), and green public procurement, to stimulate the demand side.

The project studying the problem of environmentally harmful subsidies (section 2.3) shows that eliminating, reducing and reforming direct and indirect subsidies stimulating energy use in particular, is import to get the prices right. Lack of environmental taxes is, from an analytic point of view, just another form of indirect subsidies to polluting industries and consumption. The challenge is how to safeguard and compensate the most vulnerable population groups, while this may become even more difficult under financial crises. The financial and fiscal crisis can be opportunities to carry out much-needed reforms and reorient economic growth in a greener, more sustainable direction, through reforming environmentally harmful subsidies reforms and increasing revenues from environmental taxes and charges. 
Environmental damages reducing ecosystem services is another area lacking externality pricing. One of the projects financed by the Nordic Council of Ministers looks at the status of methods and measures and the use of valuation of ecosystem services (section 2.4). The project shows that payment for ecosystem services is firmly embedded in the tool box of classical incentive-based policy instruments, and yet offers a novel way to managing ecosystem services by providing a direct conditional way of buying conservation and integrating the demand and supply sides. The report concludes that there is scope both for improving and expanding economic instruments in this field in the Nordic countries.

Green labelling and voluntary agreements are examples of "soft" instruments. A study evaluating the use and prevalence of these instruments in the Nordic countries (section 2.5) concludes that there is need for more knowledge on the effects of both these instruments. Existing evaluations are thorough and factual, but they seem to lack baseline and economic analysis. The same conclusion applies to green public procurement (section 2.6), as it was not possible to identify relevant references for the assessment of the potential impact of public procurement. Hence the reports reveal a clear need for further studies on the cost-effectiveness of green labelling, voluntary agreements and public procurement relative to economic instruments and direct regulations. Above all, such "soft" marked-based instruments need to be seen together with and actively combined with these other instruments.

Solid information on the functioning of instruments is a prerequisite for efficient policy formulation. One severe problem in environmental economics is the nature of negative externalities; the costs can per definition not be derived from market prices. Traditionally, much effort has been devoted to producing statistics on environmentally harmful emissions, and to estimate costs to human health and the environment. The costs due to reduced ecosystem services are even more complex to estimate, and have been given far less attention. As found in the project (section 2.4) mentioned above, there are many examples of payment for ecosystem services, but it is more difficult to evaluate the costs of ecosystem service damages from pollution and resource depletion. The project looking at values from Nordic watersheds (section 2.7) clearly illustrates the complications related to average value estimates for ecosystem services. For example, the modelling has to be spatially explicit to address economic interests and the locations.

Two projects were directed at development of statistics as information basis for e.g. environmental instruments. To better understand the transition to a greener economy, several initiatives have been made to measure single aspects of greenness. The first project (section 2.8), reviewing initiatives made to measure such aspects, argues that it is both theoretically and practically impossible to measure, define and delineate which jobs, companies, sectors and technologies that are "green", and, implicitly, which are not. All production and consumption of goods and services have environmental effects. Hence, "greenness" is a relative concept, which all jobs and companies contribute to along the production and delivery chains. The report concludes that existing emission inventories and national accounts offer more relevant statistics on environmental pressure across activities.

The second project evaluates different types of information and environmental indicators and their major uses, and gives guidance regarding the use of environmental 
indicators (section 2.9). The report underlines the need for caution using statistics and is a reminder and guide of for what purpose to use what statistics.

\section{Relations to the overall goals}

The Nordic Council of Ministers' Environmental action plan 2009-2012 (see section 1.1) aims to focus on climate and air sea and coastal regions, biological diversity and ecosystem services and sustainable consumption and production as key themes for environmental cooperation. The studies carried out under the Nordic Council of Ministers' research programs mentioned above together cover these focus areas. Some of the reports look at general experiences and principles for environmental policy promoting sustainable development, covering all areas. Other projects bring particularly forward the complicated field of ecosystem valuation and regulation. The focus on the development of relevant statistics also provides a general basis for all areas forwarded in the action plan.

A second leading initiative is the EU2020 Road Map on resource efficiency (see section 1.2). This strategy focusses on getting the prices right encouraging sustainable innovation, filling knowledge gaps and international consensus. This is consistent with the Nordic Council of Ministers' strategies as elaborated above.

\section{The conference}

The conference on Green economic growth in March 2012 filled in many of the conclusions from the reports financed by Nordic Council of Ministers. The conference covered three sessions. The first one, Resources, ecology and growth, included discussions on historical and potential future development of decoupling between economic growth and the environment (section 3.2.1). As stated in the synthesis report (section 2.1), there are clear signs of decoupling. But still, the environmental pressure on ecosystems increases. The extent and values of the damages are subject to exploration, and the session confirmed the need for good statistics for ecosystem services are needed (section 3.2.2).

The second session, Resource efficiency in industry, presented cases from the industries with clear resource efficiency improvements (section 3.3). The cases illustrated how increasing costs and economic motives spur innovation to more resource efficient products.

The third session, Environmental policy, innovation and technology, focussed on innovation and on correct relative prices as important incentives (section 3.4). The importance of combining and adding incentives, including support to relevant research, was emphasised. The presentations confirmed the conclusion that data on the effects of green procurement, labelling and voluntary agreements is scarce, and that there is little evidence of the effects of these instruments.

The fourth session, Where do we go from here?, discussed the similarities between the Nordic countries and China (section 3.5). Recent experiences show that China mainly uses the same tools in their transition to a greener economy as we have found efficient. This includes the instruments in focus in the Nordic work on green economy, i.e. public investment, research and development, green procurement, price incentives and tariffs.

\section{The road ahead}


The Nordic prime ministers' Working Group for Green Growth has mapped specific Nordic strengths and tangible areas for Nordic cooperation, and suggests eight main areas for joint work within the Nordic region (see section 1.3). These areas will be core topics for Nordic cooperation on green growth in the coming years. 


\section{Introduction}

In the presence of a rapidly rising global population and the threat of increasing environmental pressure in general, and global warming in particular, the environmental problems has got increasing attention on the international political agenda. A transition to a future with lower greenhouse gas emissions and other environmental damages calls for a greening of the economy, i.e. more environmentally friendly production an consumption processes and technologies. The emphasis on reduced environmental pressure conflicts with the urge for economic growth, particularly in developing countries. The financial crises may contribute to downgrade the environmental ambitions also in developed countries. The challenge is how to combine actions to meet climate change and other environmental challenges to obtain a more sustainable economic development, in both developed and developing countries.

The Nordic Council of Ministers has a long tradition for highlighting solutions to the environmental challenges in their working groups, research programs and publications. This reports aim to summarize some of the recent work on greater resource efficiency and greener economic growth and development in the Nordic countries. This includes core background documents from the Nordic Council of Ministers, The Nordic prime ministers' Working Group for Green Growth, and the EU (chapter 1), research studies related to green growth financed by the Nordic Council of Ministers (chapter 2), and the Oslo conference on Green economic growth held in March 2012 (chapter 3). 


\section{Background}

This section summarizes the main background reports to the Nordic work on green economy. These include The environmental action plan 2009-2012 (Nordic Council of Ministers 2008), the EU2020 Strategy with its Road Map on resource efficiency (EU 2011) and the report from The Nordic prime ministers' Working Group for Green Growth (2011).

\subsection{The environmental action plan 2009-2012}

The environmental action plan 2009-2012 (Nordic Council of Ministers 2008) emphasises the ambition of the Nordic countries to be a pioneer region in the environmental area and in sharing their experience with others. Through coordinated efforts, the Nordic countries have contributed initiatives and tested problem solutions to the international environmental challenges. The plan points to the need to further continue and develop this work method, to enhance cooperation between the Nordic countries to optimise the utilisation of available resources and to find joint solutions in the Nordic region.

The choice of areas for Nordic cooperation rests on the principle that the cooperation can improve the results or save resources compared with the situation where the countries act alone. The plan points to four main themes for environmental cooperation during the period 2009-2012:

- Climate and air: Serious changes in the earth's climate must be averted and the effects of climate change prevented. The content of pollutants in the air must not harm the environment or human health.

- Sea and coastal regions: The Nordic waters must have a good ecological status by 2020. The Nordic waters must be utilised sustainably.

- Biological diversity and ecosystem services: Sustainable management of the natural environment must be achieved for the purpose of protecting natural processes and the value of the cultural landscape to maintain ecosystem services.

- Sustainable consumption and production: Consumption and production must take place in such a manner that environmental and health conditions can be improved and resource utilisation is efficient and sustainable.

Throughout this report, we will examine how the overall objectives within these themes have been captured by the initiatives made by the Nordic Council of Ministers.

\subsection{The EU2020 Strategy with its Road Map on resource efficiency}

The EU2020 Strategy with its Road Map on resource efficiency (EU 2011) is another important guideline for the Nordic work. The Vision of the road map is that by 2050 the EU's economy has grown in a way that respects resource constraints and planetary boundaries, thus contributing to global economic transformation.

\section{Towards resource efficient policies}


The Road Map emphasises the need for transforming the economy in order to remove barriers holding back resource efficiency and to create the right incentives for production and consumption decisions. The vision is that by 2020 , citizens and public authorities have the right incentives to choose the most resource efficient products and services, through appropriate price signals and clear environmental information. The report points to the need for policies that balance the natural capital and the removal of barriers to improved resource efficiency, with a fair, flexible, predictable and coherent basis for business to operate. Four main suggestions are forwarded:

- To address markets and prices, taxes and subsidies that do not reflect the real costs of resource use and lock the economy into an unsustainable path. As a milestone for 2020, environmentally harmful subsidies have been phased out, and taxes shifted from taxation of labour towards environmental taxation.

- To encourage more long-term innovative thinking in business, finance and politics that leads to the uptake of new sustainable practices and stimulates breakthroughs in innovation, and develops forward thinking, and cost effective regulation.

- To carry out research to fill the gaps in our knowledge and skills and provide the right information and training. As a milestone for 2020, scientific breakthroughs and sustained innovation efforts have dramatically improved how we understand, manage, reduce the use, reuse, recycle, substitute and safeguard and value resources.

- To deal with international competitiveness concerns, and seek to get a consensus with international partners to move in a similar direction.

In order to get the prices right, evaluation of non-market goods can provide important guidelines for market adjustments. The report emphasises the need for valuation and accounting of ecosystem services.

\section{Sector-wise milestones}

Milestones for 2020 are set up for particular areas:

- Waste should be managed as a resource and illegal shipping of waste should be eradicated.

- The loss of biodiversity and degradation of ecosystem services should be halted and biodiversity restored as far as feasible.

- The Water Framework Directive is implemented and impacts of droughts and flood minimised.

- The EU's interim air quality standards will have been met.

- The EU policies take into account their direct and indirect impact on land use with the aim achieving no land take by 2050 .

- Good environmental status of all EU marine waters is achieved and fishing is within maximum sustainable yields.

- Widespread incentives to healthier and more sustainable food production and consumption.

- High resource efficiency in renovation and construction of buildings and infrastructure.

- Transport will use less and cleaner energy with reduced negative impact on the environment. 
The Road Map further provides a detailed framework illustrating the inter-linkages between key sectors and resources and their associated EU policy initiatives.

\subsection{The Nordic prime ministers' Working Group for Green Growth}

The Nordic Working Group for Green Growth was issued by the Nordic prime ministers. Their mandate was to map specific Nordic strengths and tangible areas in which Nordic co-operation creates or has the potential to create synergy. In their report, they suggest eight main areas for joint work within the Nordic region (The Nordic prime ministers' Working Group for Green Growth 2011):

- Develop Nordic test centres for green solutions:

So that energy technologies can be tested and developed on a large scale, and also to study the opportunities and added value to be derived from establishing new joint Nordic test and demonstration facilities.

Responsible ministries: Energy, with trade, research, transport and agriculture.

- Work together on education, training and research for green growth:

To map the opportunities and quantify the added value of working together on national education, training and research initiatives of significance to green growth.

Responsible ministries: Education and research, with energy and trade.

- Promote flexible consumption of electricity:

To reinforce the focus on the demand side, e.g. promote flexible consumption of electricity and a Nordic exchange of experiences, and to promote partnerships with leading stakeholders in industry and the service sector in order to share experiences and best practice.

Responsible ministries: Energy, with trade.

- Work together on green-technology norms and standards:

Identify the most important areas in construction in which technical norms and standards would be suited to co-ordination at Nordic level, and to develop proposals for how the barriers to this work could be removed, and to raise the level of ambition in EU work on eco-design and energy-labelling requirements for various types of products.

Responsible ministries: Trade, energy, housing and environment.

- Work together on green procurement in the public sector:

Identify areas and product groups in which green procurement standards are most efficient in comparison with other instruments, and study the opportunities for coordinating green procurement standards at Nordic level.

Responsible ministries: Trade, with environment and energy.

- Develop techniques and methods for waste treatment:

Develop joint Nordic methods and technology for selected types of waste in which there is known potential for a resource-effective life cycle in the wastetreatment sector.

Responsible ministries: Environment, with energy and trade.

- Promote the integration of environmental and climate considerations into development aid:

Reinforce the green emphasis and study opportunities for the further development of the Nordic Climate Facility. 
Responsible ministries: Aid/development ministers.

- Coordinate and improve funding for green investment and companies to support funding for growth in green companies and investment:

Responsible ministries: Finance, with trade and energy. 


\section{Projects initiated by the Nordic Council of Ministers}

This chapter summarizes the main findings in the research studies related to green growth financed by the Nordic Council of Ministers.

\subsection{Greening the economy: Nordic experiences and challenges}

All of the background initiatives in chapter 1 emphasise the challenging policy requirements needed to balance environmental and resource values with the needs for economic growth. The project "Greening the economy: Nordic experiences and challenges" (Skjelvik, Bruvoll and Ibenholt 2011) looks into the experiences in the Nordic countries with respect to greening the economy over the previous decades. The report focusses on how economic instruments have contributed to integrate environmental concerns into economic growth and development policies.

The report demonstrates that the Nordic countries over the last decades have achieved a decoupling of economic development from growth in emissions. Several major pollutants have been substantially reduced along with clear improvements in local and regional environmental quality, while maintaining an internationally respectable rate of economic growth. This has been achieved through a range of policy instruments, with a strong and increasing element of economic, marked-based instruments.

There are many examples in the Nordic countries of lacking instruments, or that the instrument did not provide the correct incentives. To include payment for ecosystem services into the market based scheme is one example. There is significant scope for using such payment to promote private sector engagement in biodiversity conservation. The report concludes that it is both a challenge and opportunity for the Nordic countries to improve efficiency in policy design of and in the combination of policy instruments.

It is recommended that the need for subsidies should be critically assessed. Subsidies should be used to create incentives to generate an optimal level of positive externalities, which are normally present during the $R \& D$ phase. The introduction of new technologies however, should be left to the market rather than picking the winners in subsidy schemes.

The report recommends consideration of new ways of redistributing or recycling the revenues from environmental taxes. While reducing tax revenue might not be in compliance with first best solutions, it can offer second best solutions securing cost effective emission reductions, cf. the Norwegian $\mathrm{NO}_{\mathrm{x}}$ fund.

The report has some specific recommendations directed at the Nordic and other industrialized countries, and some for developing countries:

\section{Recommendations for Nordic / other developed countries}

- Global cooperation based on national responsibility is crucial to reduce GHG emissions.

- Biodiversity loss should be handled locally

- Curbing use of hazardous substances needs international cooperation.

- Local car traffic needs special attention. 
- Car taxation and costs should be more transparent to consumers.

- Tax exemptions should be removed.

\section{Recommendations for emerging / developing economies}

- Assess the costs of environmental degradation.

- Remove environmental harmful subsidies.

- Consider imposing local resource management and fuel/emission taxation.

\subsection{The economic crisis and its consequences}

As is pointed out by the background initiatives in chapter 1 , it is a particular challenge to balance the environmental and resource problems with the needs for economic growth. This problem is more relevant than ever before due to the financial crises. A first order effect of the crisis has been reduced economic growth, with emission reductions as a result. However, environmentally friendly investments will face lower priority in favour of general investments promoting economic growth. The challenge is to formulate policies stimulating both economic growth while still taking care of the environment.

The project "The economic crisis and its consequences for the environment and environmental policies" presents a review of the effects of the crisis on environmental policy and on the environment in the Nordic countries, followed by an analysis of various possible policy interventions aimed at mitigating adverse effects. The report (Berghäll and Perrels 2010) contains a quick review of typical mechanisms and effects, based on a literature survey as well as on a scan of recent trends in key economic and environmental statistics in Nordic countries.

The report states that some Nordic countries were hit more severely by the economic crisis than others, owing to different economic structures and monetary policies. Recovery has been rather hesitant. Crises usually set in motion significant changes in the structure of the economy and its institutions, which constitute both risks and opportunities.

The reduction in global energy demand caused a reduction in fossil fuel prices, whereas also prices of carbon emission rights in the European Emission Trade System (EU-ETS) decreased as a result of lowered projections of overall emissions in the near term future. As a consequence the use of coal in electricity generation increased, thereby partly offsetting the original reduction in greenhouse gas emissions. The Nordic countries taking part in EU-ETS are expected to fulfil their reduction obligations for the period 2008-2012 more easily. It seems that other emissions show less sensitivity to the economic crisis. This is partly attributable to activities such as food production, of which the physical volumes depend much less on economic cycles.

\section{Recovery policies}

The reduction in emission levels may be a temporary scale effect, and after some years the emissions will likely start to grow again. If environmental investment efforts are slowed down due to the crisis, the resumption in growth of environmental burdens may even be significant. This kind of concerns motivated many governments and specialists around the world to consider how economic stimulus packages could be made "green". On the other hand these stimulus packages are supposed to have only a limited life span, 
whereas the economic conditions for both public and private investments probably imply a substantially reduced manoeuvring space for large efforts in various environmental policy areas. This prospect invites to consider what kind of policies could overcome these obstacles for envisaged increased environmental policy efforts.

The report concludes that recovery policies, even when "green", should be distinguished from long term policies aiming at a sustainable transition, inter alia creating a lowcarbon society. The former type of policies focuses on economic growth, the latter on structural change. Careful selection and dosage of measures will help to ensure that recovery policies also promote sustainable transition.

The report shows that also the Nordic countries apply stimulus programmes with green elements, except Iceland which has not prioritized stimulus programmes due its domestic banking crisis. Outright green stimulus programmes will expire fairly soon, but for the medium to long term changes in fiscal policies may be expected, which can also offer opportunities for "greening" public finance policy.

A common element for most if not all Nordic countries is a further shift towards socalled "ecological tax reform", i.e. taxing environmentally burdening activities more and taxing labour income less.

Fiscal policy is expected to tighten considerably in all Nordic countries and elsewhere, as the crisis led to significant increases in public debt, whereas the ageing of the population adds further pressures. This creates possibilities to continue ecological tax reform as well as to diminish or abolish environmentally harmful subsidies. Furthermore, in addition to emission trade other quasi market instruments and informational instruments may gain importance.

In conjunction with expected tightening of public finances and capital markets in general, this easing effect could result in a slowdown of a sustainable transition in the Nordic countries as well in Europe overall, unless environmental policies and the greening of the fiscal policies are emphasized sufficiently. The report points to a quite large portfolio of environmental technologies and services where the Nordic countries have strong positions in export potentials and green product and service areas. These areas would need continued support for their R\&D efforts and for demonstration projects.

In short the report suggests that the following adaptations could be considered:

(1) tax reforms, with evermore stress on taxing consumption of (natural) resources and only limited (temporary) overall increase of tax rates,

(2) abolishment or at least reduction of environmentally harmful subsidies,

(3) other quasi-market incentive structures (tradable certificate systems; performance dependent "fee bates"),

(4) radical improvement of market information via monitoring and feedback services, certified labelling, etc. and

(5) combinations of the aforementioned options. 


\subsection{Reforming environmentally harmful subsidies}

An important part of sustainable policy is to remove or adjust environmentally harmful subsidies. In particular, subsidies to fossil fuel consumption are widespread around the world and contribute to significant environmental costs. Such subsidies are hard to remove, since they are used to support low income groups or out of other distributional concerns. In a transition to a more efficient environmental policy, more information on well-functioning reforms are needed.

The project "Reforming environmentally harmful subsidies" gives an overview on environmental harmful subsidies, subsidy reforms and how to counteract distributional impacts (Bruvoll, Skjelvik and Vennemo 2011). The report discusses the theoretical principles for an efficient environmental and redistribution policy, and offers a survey of experiences from policy reforms over a range of countries. The reform survey forms a background for recommendations of sustainable policy reforms, taking care of environmental, economic and distributional concerns.

The phase-out of fossil fuel consumption subsidies would reduce global energy-related carbon emissions by about 6 per cent. The burden on public budgets is particularly high in developing countries. The total order of magnitude of fossil fuel subsidies is roughly estimated to almost 1 per cent of world GDP.

The review of environmentally harmful subsidies shows that the most common justification for subsidies to energy consumption is to support low income groups. Developed countries face higher environmental awareness and higher willingness and economic possibility to prioritize the environment. The Nordic countries are among the richest in the world, and typical characteristics are strong public sectors. Though environmentally harmful subsidies seem to be more common as support to industries, employment and regional development, the total environmental impact is probably relatively lower compared to most other countries.

\section{Definition of environmentally harmful subsidies}

The report draws theoretical lines for the definition of environmentally harmful subsidies. The main recommendations are that:

- Environmentally harmful subsidies are inefficient subsidies causing negative environmental effects.

- Subsidies correctly levied to adjust for market failure or in order to correct distributional impacts should not be included in the definition of a harmful subsidy, despite their possible negative environmental effects.

- Exemptions and lack of environmental taxes and regulations, in addition to several non-budgetary support mechanisms are also principally environmentally harmful subsidies.

\section{Policy recommendations}

Normally, subsidies are thought of as direct support over public budgets. But indirect support and polluters not paying the external emission costs are just other forms of environmentally harmful subsidies. Lack of environmental taxes, selective exemptions from governmental standards, preferential market access and price support represent 
different types of off-budget subsidies with principally the same effects as direct subsidies. Hence reducing the extent of environmentally harmful subsidies involves more than only removing the on-budget subsidies. Indirect subsidies and tax exemption should also be removed, and polluting activities should be fully taxed according to their external costs.

The core of the problem related to environmentally harmful subsidies is that the support benefits significant groups. Removing the subsidies normally provokes opposition from pressure groups and political parties. First, it is necessary to identify which groups are in target for support. In reality, subsidies to fossil fuel consumption first of all benefits those who can afford to use energy-intensive appliances, not the poor. To raise the necessary political support, it is important to produce high quality, reliable information about the benefits and costs, in order to communicate the net benefits to the society, and to be clear about the political targets. Adversely, it has been shown that lack of transparent information has been a decisive obstacle to reforms. Predictability and broad political support increase the possibility of implementing sound reforms.

The environmental and economic costs and benefits should be evaluated to help prioritize reforms. The original purpose of the subsidies must be identified in order to evaluate whether compensatory measures are required to uphold the political goals.

Compensatory measures have proven to be of crucial importance in successful reforms of harmful subsidies around the world. Reducing harmful subsidies improves the public budgets and releases funding for direct compensation packages. To avoid new, inefficient subsidies, it is important to levy the compensation as close to the prioritized groups as possible. It is also important to avoid new environmentally harmful subsidies, such as the different forms of subsidies for new energy forms, which always have some negative effects. Instead, emissions should be subject to direct taxes.

\subsection{Payment for and management of ecosystem services}

Payment for ecosystem services (PES) gives the owners of natural resources direct incentives to manage it in society's best interest, given that the prices reflect the social marginal costs including environmental consequences. Such payment can imply that the resource owner gives up some private income in exchange for a compensation for the ecosystem services. While environmental taxes are increasingly used to get the prices right, PES is an emerging policy alternative to direct regulations. Since experiences with PES are rather scarce, there is a need for an overview to increase the scientific basis for more widespread use of economic instruments.

The project "Payment for and management of ecosystem services" provides an overview of the status of methods and measures in the valuation of and payment for ecosystem services and gives examples of such payment systems or other similar management mechanisms (Zandersen, Grønvik Bråten and Lindhjem 2009). The study provides policy makers as well as the wider public advice and recommendations on how such methods and systems can be applied in different areas and for different types of ecosystem services.

It is shown that PES is firmly embedded in the tool box of classical incentive-based policy instruments and yet offers a novel way to managing ecosystem services by 
providing a direct conditional way of buying conservation and integrating the demand and supply sides of ecosystem services. PES is found either in the form of nature conservation contracts or as creation of new market products such as offset credits or eco-labelling.

The report proposes to use a distinction between intermediate and final goods of nature in helping to set up efficient PES schemes. It identifies at an overall level the beneficiaries of ecosystem services, distribution of rights between buyers and sellers of ecosystem services and public-private good aspects of ecosystem services, and it proposes a framework for integrating ecosystems and economic values. A number of examples of PES from OECD countries are presented to show the variety in PES contract designs and two in-depth case studies from Denmark and Finland illustrate different experiences in the Nordic countries with PES.

The report concludes by arguing there is scope both to improve and expand the current use of PES in the Nordic countries.

\subsection{Voluntary agreements and environmental labelling in the Nordic countries}

While the standard advice from economic experts is to get the prices right, supplementary "soft" instruments are popular policy alternatives to rising costs through environmental taxes. The optimal choice between instruments requires information on the cost efficiency of the alternative instruments. Pigouvian taxes are per definition cost effective, if formulated in accordance with theory. The cost-efficiency in soft instruments, as voluntary agreements and eco labelling, is however difficult to investigate.

The project "Voluntary agreements and environmental labelling in the Nordic countries" (Bauer and Fischer-Bogason 2011) map the use and prevalence of eco-labels, environmental voluntary agreements in the Nordic countries, and the inclusion of these specific tools in policy mixes.

The study reveals that voluntary agreements and Eco-labelling Schemes are in use in all the Nordic countries. Especially Denmark, Sweden and Norway have made numerous experiences in the use of these soft regulatory instruments. Whereas the development and implementation of voluntary agreements is ad hoc based, Eco-labelling is a quite well developed policy tool and especially the Nordic Swan is well known in the Nordic markets and has increased the number of licenses in the recent years.

\section{Voluntary Agreements}

The use and effects of the voluntary agreements are not well documented in any of the countries; evaluations are few and data are quite poor. Only few evaluations on the cost effectiveness have been identified, all stating that cost effectiveness is difficult to assess; not least caused by a general lack of data and lack of comparables and baselines. Moreover, it is difficult to isolate the effects of the agreements. The conclusions that are made state that the studied agreements are considered cost effective either in terms of "expected costs" or in comparison to other measures. Cost effectiveness seems to be a 
strong argument for drawing and entering the agreements. Evaluations of the effects of voluntary agreements on society level are not seen.

\section{Eco-labels}

Eco-labels are evaluated on different levels, but actual environmental effects of the schemes are not documented. No analyses have been identified on the cost effectiveness of The Nordic Swan and the EU-Ecolabel.

\section{Policy mixes}

There are not many examples of strategic use of voluntary agreements or eco-labelling with other policy instruments, and policy-mixing has not been thoroughly addressed in the existing evaluations. Successful cases of policy mixes are mainly found within energy efficiency, linking energy efficiency agreements with instruments such as environmental permits, green taxes and information campaigns. More experience and analyses of the combination of policy tools are needed.

Concerning eco-labelling there are good examples and a large potential in using the labelling criteria in public tenders. The mappings show that little knowledge exists on the environmental effectiveness of policy mixes of voluntary agreements and eco-labels. It is concluded in other studies that the use of policy mix is particularly relevant when aimed at environmental problems that are of a "multi aspect" nature.

\section{Need for knowledge}

The main conclusions are that there is a need for more knowledge on the actual economic and environmental effects of both voluntary agreements and eco-labelling schemes. The existing evaluations are thorough and factual, but they lack baseline and economic analysis. Systematic monitoring and evaluation processes must be carried through on a regular basis in order to gather valid data and a form a knowledge base from which practitioners can learn. It is also concluded that policy mixes with these instruments are rare and seldom intended. The study of available evaluations shows that it is essential to develop structured methods for monitoring and evaluating both the voluntary agreements and the eco-labelling schemes.

\subsection{Benefits of green public procurement}

Public procurement is a frequently discussed instrument to influence the private sector towards more sustainable products and services. Bauer et al. (2009) identify product groups for which green public procurement can serve as an effective regulatory instrument, and illustrate the potential impact of green public procurement (GPP).

Public procurement constitutes 16 percent of GNP in the Nordic countries and for certain product groups the public sector is the most significant purchaser. However, it has not been clarified so far in which areas public procurement is most efficient, in other words where the largest environmental result can be obtained with the lowest cost. The project was initiated to identify product groups for which green public procurement is an effective regulatory instrument, and to illustrate the potential impact of GPP. 
The report defines some products with a large turnover and significant environmental impact; construction works, IT products, cleaning agents, transport services and vehicles.

The report states that it was not possible to identify relevant references for the assessment of the potential impact of existing and optional regulation, including GPP. Hence the project does not provide answers to the cost-efficiency in GPP relative to other instruments.

Although the report points out some positive features, such as flexibility and reversibility, these features also apply for economic instruments and direct regulations. The report also point to challenges related to GPP. The procurement costs are higher for green products. It is necessary to address structural and legislative barriers to GPP and, opposed to legislation and taxes, it requires special competences by public procurement officers.

The report reveals a lack of information of benefits and costs related to green public procurements. The core question is how resources directed at environmental improvements can maximise the environmental benefits. Even though GPP may reduce emissions, this offers no information about the effects of alternatives. More research is needed as background for evaluation of GPP as an environmental policy instrument.

\subsection{Valuation of ecosystem services from Nordic watersheds}

The environmental action plan (section 1.1) emphasises the need for improving the ecological status in the Nordic waters in sea and coastal regions, and also the EU Road Map (section 1.2) prioritizes sustainable management within biological diversity and ecosystem services. The valuation of environmental damages is a crucial prerequisite for getting the prices right by using environmental taxes and direct regulations. Environmental economics has long tradition for theoretical and empirical works within evaluation of negative externalities related to pollutants, but the negative consequences on ecosystem services are less studied. Valuation of ecosystem services is thus an important research field to include the broader range of environmental externalities in an efficient policy framework.

The project "Valuation of ecosystem services from Nordic watersheds" (Barton et al. 2012) responds to a need for a Nordic synthesis of experiences with valuation of ecosystem services from watersheds. The objective of the report from the project is to estimate the scope of economic values of ecosystem services in selected watersheds as decisionsupport for specific policy scenarios and for general demonstration of the importance of such services.

The main findings are that the watershed ecosystem services valued are quite similar across the Nordic countries. The services addressed are mainly provisioning services as food and fresh water supply, as well as cultural services as aesthetic information and opportunities for recreation and tourism. However, valuation studies of regulating and supporting habitat services seem to be under-represented.

The authors argue that valuation studies framed to address economic analysis of a particular policy respond to a different policy need than studies aiming at calculating 
average per hectare values of ecosystems. Commissioned valuation studies must start by addressing what kinds of policy they are aimed at informing as a function of how reliable and accurate the valuation method has been found to be relative to policy requirements. Be-yond using valuation studies as information for framing policy debate through raising awareness, it should be made clear whether specific studies of valuation of ecosystem services are to be used for accounting, priority-setting or instrument design.

Associating values of water quality to states of the ecosystem involves combining pressure-state-impact modelling of run-off from land and water uses to status of water bodies. The focus on valuing ecosystems contribution to human well-being while laudable, must avoid a focus on trying to isolate the value of "natural" ecosystems if this is at the expense of tried and tested methods such as cost-effectiveness analysis.

The authors therefore argue that calculation of average per hectare ecosystem services values may be useful for awareness raising and accounting at aggregate levels. However, it is not useful for the part of policy addressing priority-setting and instrument design. Modelling of regulating services such as flood reduction and pollution control needs to be spatially explicit if it is to address economic interests and their locations, and in turn be policy relevant. Different interests live and use different "hectares" of an ecosystem. Average values of ecosystem services do not address income distributional issues, but cover conflicts of interest between different users using the same ecosystem and tradeoffs between them.

Economic valuation is useful for instrument design if it can help predict how similar incentive levels would lead to different behaviour of different interests at different locations; or how to target incentives across interests and locations in order to achieve similar behaviour. Priority setting between alternative land-uses, projects, and measures is at its core identifying how land and water use values differ between interests at specific locations.

Ecosystem services are in part defined by policy regulation. Particularly in high income countries such as the Nordic, health and safety standards probably play a large part in how we perceive nature. Regulations define what rights private interests have to ecosystem services, to public measures to provide these services, and to compensation if these are lost. Establishing these rights through regulation is costly. However, valuation of ES seldom addresses the transaction costs of defining ES as rights. Policy relevant valuation research includes research on transaction costs of payments of ES.

\subsection{Measuring green jobs?}

The demand for data on green activities in many forms is driven by the need for international comparisons, and to track progress on environmental progress in different companies, sectors, companies and the economy as a whole. Environmental authorities and politicians ask for information to demonstrate the effects of environmental policies. Countries with high unemployment seek new business opportunities and additional jobs for economic growth.

As a response to the need for information helping us to understand the transition to a greener economy several initiatives have been made to measure "green sectors", "green jobs" and "green technologies". There is no commonly agreed definition across the 
different initiatives made to measure the green factors. Hence, there is a need to clarify and structure relevant concepts to improve the information asked for.

The project «Measuring green jobs? An evaluation of definitions and statistics for green activities» reviews initiatives made to measure these aspects (Bruvoll et al. 2012). The report discusses whether the statistics collected under the present initiatives increase insights into the fundamental questions motivating the initiatives, and looks into information on future economic structures and needs for educated labour to meet environmental challenges. Suggestions are made on which data would be best suited for producing the relevant information.

In particular, the report evaluates the UN/Eurostat initiative EGSS (Environmental Goods and Service Sectors), which is a comprehensive attempt planned to become an international standard for quantification. The report concludes that it is both theoretically and practically impossible to measure, define and delineate which jobs, companies and sectors that are "green", while other jobs, companies and sectors are not. Since all production and consumption of goods and services have environmental effects, "greenness" is a relative concept. All jobs and companies are part of long production and delivery chains involving many companies and sectors, and all activities cause environmental damages to some extent.

\section{Alternative statistics}

The core issue of green growth is not the relative size of "green" sectors, but the aggregate environmental impacts of the whole economy. The report illustrates that the use of conventional statistics covers all the information needs requested by politicians, including factual data on emissions, resource, employment and production, and enable measurements of environmental load and related employment per sector without creating normative categories for which activities are green and non-green. The UN SEEA and, in particular, the European NAMEA system, applied in several Nordic countries, provide frameworks for using and further developing such data, and can also be used for linking to macro-economic modelling and analysis of highly relevant environmental policy issues.

A consistent way to use the statistics could be to calculate the environmental damages per produced unit of different sectors and track the development over time. This can be done by using traditional statistical methods and data. Emissions and other damages may be weighed together using cost estimates from the literature, to form estimates or uncertainty intervals for the more overall environmental pressure, if such information is requested.

Finally, economic models offer forecasts for potential economic and environmental development, and hence the need for environmental instruments and policy to stimulate relevant competence development.

\section{Education needs}

The report further looks at present and future economic structures and needs for labour to meet environmental challenges. As a general trend in the Nordic countries, jobs are getting more knowledge intensive. This does not necessarily correlate to 
environmentally friendly technologies, since these require both low and high skilled jobs. From a policy point of view it is difficult to point out specifically which types of education will be most important to support in the future in an environmental perspective.

\subsection{Using the right environmental indicators}

To formulate responses to environmental impacts, comprehensive and accessible information is needed. However, the environmental information is often a puzzle with many different pieces found in various ministries, agencies and institutions involved in the development and publication of data, statistics and indicators. Making sense of this information, keeping track of who is doing what and figuring out what information is needed and when to use which type of indicator can be challenging.

The project "Using the right environmental indicators" attempts to evaluate different types of information/indicators and what are their major uses (Hass and Palm 2012). Further, it looks at the work of the Nordic countries in light of the System of Environmental-Economic Accounting (SEEA), the related 2011 EU regulation requiring reporting of environmental accounts and the proposed new reporting areas that are under discussion with the European Commission (Eurostat). In addition to describing the different types of indicators, some evaluation and guidance regarding the use of indicators are given.

The main conclusions and recommendations in the report include:

- Indicators need to be used appropriately. For example, indicators which are best used for awareness-raising cannot be appropriately used for monitoring policies.

- Statistics used for monitoring need to be constructed specifically to address and keep track of policy goals.

- Complex, aggregated indicators are typically only appropriate for awarenessraising, and data quality and international comparability are often questionable.

- Attempts to develop "Green GDP" figures encounter a range of problems, above all that all valuation methods proposed for assigning prices to environmental goods and services yield prices that are not consistent with and cannot be added to the market-based prices in the present system of national accounts.

- These problems also arise for attempts to integrate the value of ecosystem services in national accounting. While much useful work has been done and can be further developed on identifying and describing physical ecosystem services, in measuring the amounts and the importance of such services to human users and stakeholders, and in analysis and evaluation of the different types of "value" of these services, the fundamental problem of incompatible types of prices remains a stumbling block to full integration in national accounting.

- The statistical offices of the Nordic countries have a long history of working with "satellite accounts" for the environment, in combining national accounts with environmental information, and in modelling and analysis of a range of environmental issues, based on linking such national accounting and environmental data. These systems and methods may be the best approach to respond to the needs and demands of policy-making that "Green GDP"-efforts are sometimes put forward as an answer to. 
- On proposed new modules in the European Union legal framework on environmental-economic accounts, the report supports a module on energy use by economic actor, with some modifications, sees the detail required for a module on Environmental Goods and Services as a determining factor in its acceptance, and suggests that data needs for a new module on environmental protection expenditure could be met by current required reporting.

- In relation to further development of existing modules, the report strongly recommends that priority on material flow accounting move from overall economy-wide figures to substances with less mass but higher environmental impacts, such as hazardous chemicals.

These conclusions and recommendations might form part of the basis for Nordic contributions to further work in the OECD (e.g green growth indicators) and in EU/Eurostat (indicators for resource efficiency, environmental-economic accounts).

\subsection{Environmental technologies in the Nordic countries}

Environmental improvements basically rely on technological development and adaptation. For example, emission reductions per unit of energy used will be crucial in the future solution to global warming, either as new sources of energy, or more efficient energy technologies.

The project "Environmental technologies in the Nordic countries" aims to describe the Nordic countries' efforts to promote eco-efficient technology or environmental technology (Skov 2012). The report emphasises the solutions of environmental problems rather than the business potential, and assesses the status and possibilities for improvement for each Nordic country. The report further looks at differences and similarities between the Nordic countries, and assesses whether there are opportunities for better cooperation to move forward by the help of others.

The report recommends more environmental information on companies and their export and patents, in addition to information on the amount of funding, how it has been used and dissemination of the outcomes. The report also asks for sufficient grant funds and venture capital to meet the reasonable needs of companies, more regulation of the demand side, including green public procurement, coordination between state actors and nations, and strategies for green growth. 


\section{The conference}

As part of the Norwegian chairmanship of the Nordic Council of Ministers in 2012, the Norwegian Ministry of the Environment arranged a conference on Green economic growth in March 2012. The conference built on recent Nordic and international work on greening the economy and on green economic growth.

The aim of the conference was to discuss how to deepen and strengthen efforts to achieve greater resource efficiency and greener economic growth and development in the Nordic countries, and, in particular, how to follow-up both the EU2020 Strategy with its Road Map on Resource Efficiency and the report from the Nordic Prime Ministers' Task Force on Green Growth, cf. Chapter 1.

The conference included presentations from UNEP's International Resource Panel, from the European Union, on the Road Map on Resource Efficiency, and from the OECD, on the role of innovation in OECD's Green Growth Strategy, in addition to presentations based on the Nordic Council of Ministers' own work on a Green Economy, cf. Chapter 2. The conference concluded with a discussion between a panel and the audience, on how to promote environmental technology, resource efficiency and green economic growth in the Nordic countries.

This chapter summarizes the main content of the conference, including the presentations and the penal debate.

\subsection{Introduction}

Erik Solheim, the Norwegian Minister of Environment and International Development opened the conference. The Minister referred to the positive historical aspects of international development, as the world has reached less poverty, more peace, more fair democracy, better health, and higher education level than in any other part of history. The next problem now is how the western world should solve the industrial pollution problem.

At the same time as we are in the fortunate situation of high economic capacity, it is uncertain whether we manage to solve climate change, and whether we have the capacity to come together and agree. It is also uncertain whether Europe and USA are able to solve the economic challenges following the financial crisis. The world has also become politically multi-polar world, which is more fair, but this framework is also more difficult to agree within than before.

Still 1 billion people live in poverty, and economic uncertainty. The minister pointed to green inclusive growth as the answer to this problem. We need growth to get countries like India out of poverty, but the growth has to be green, otherwise it will be undermined.

The largest challenge is that private profit from utilizing ecosystems brings great benefit to privates. He pointed to socialized costs, i.e. more fair economic systems, as a solution, for example profits from ecosystems must be shared by taxes, also taking care of future generation. The Minister referred to the Nordic model and its ability to find 
compromises. The cooperation between industrial leaders, unions and the state is unique to the world, the ability to agree is a great Nordic advantage, and he claimed that the Nordic countries are less fearful of change than other societies, including changes in industrial behaviour.

The Minister pointed to several important strategies to solve the conflicting interests between growth and environment. First, he stated that it will be necessary to decouple the economy. We need economic growth, as there no theory of how to improve the economies without growth. Nearly all pollutants have been decoupled from economic growth, and most have substantially decoupled since the 1990s. A crucial point is to become more resource efficient.

Further, he pointed to the large potential in rainforests preservation. In Brazil, deforestation has been reduced by 70 percent in 7 years. This is the most impact any country has ever made to reduce GHG and to preserve biodiversity. Another initiative, made by Sweden and USA, is to reduce short-lived climate drivers.

Finally, he mentioned Ban Ki-moon's global initiative to create a global right to sustainable energy. 1,4 billion people have still no grid connection. This cannot be based on coal, but must be renewable. Huge green scale investments must be done with public financial aid, in cooperation with private interests.

\subsection{Session 1: Resources, ecology and growth}

The two first speakers in this session focussed on particular aspect of green growth; Edgar Hertwick discussed the historical and potential future development of decoupling between economic growth and the environment, and Marianne Kettunen discussed the measurements of benefits from ecosystem services. While we find clear signs of decoupling, the environmental pressure still increases. This harms ecosystems, but the extent and values of the damages are still subject to exploration. To implement the correct signals to the market and to formulate efficient regulations, good statistics for ecosystem services are needed. This is reflected in the initiatives following the background documents for the Nordic work on green economy, see The environmental action plan (section 1.1) as well as the EU Roadmap (section 1.2).

The last two speakers presented programs supporting initiatives for green growth. Janos Herman presented the EU Roadmap for green growth, and Øyvind Lone presented the Nordic prime Ministers' Task Force on Green Growth, which looks into potentials for increased governmental cooperation on green growth.

\subsubsection{Global resource use and decoupling}

Edgar Hertwich, UNEP's International Resource Panel, discussed the issue of resource use and decoupling. He claimed that there may be ways to decouple the environmental impacts and resource use from economic growth while at the same time avoiding burden shifting between countries, generations and trade-offs between impact categories and life cycle stages.

Hertwich participates in UNEP's International Resource Panel, which has launched five assessment reports, from which he referred the results: A key finding is that GDP has 
grown faster than material extraction over the last 100 years in all the categories of the investigated material extractions (ores and industrial materials, fossil energy carriers, construction materials and biomass). At the same time, resource use per capita has increased, and resource use per capita grows by income. The increasing trends hold across expenditure categories; the carbon emissions increase with income. The Panel estimates an elasticity between carbon emission and income of 0,73 , and a relative decupling between household income and energy use.

Hence, the findings in this project, as well as in other parts of the literature, show that there is a relative decoupling between resource use and GDP. There is however no signs of absolute decoupling. At present, consumption growth outstrips decoupling, leading to an increase in absolute resource consumption.

Generally, resource prices fell towards 1990, but statistics indicate increasing prices the last decades. This may be a sign of scarcity, which may promote efficiency improvements. In his conclusion, Hertwich pointed to the fact that, despite decoupling, emissions increase due to the increasing scale of the economy. A more controversial alternative is to focus on decoupling of wellbeing from resource consumption. This implies not using economic growth as a meter of growth in wellbeing, but accepting that human welfare can increase without increasing GDP.

\subsubsection{The value of ecosystem services}

Marianne Kettunen, Finnish Environment Institute and Institute for European Environmental Policy discussed the values and the valuation of ecosystem services. Ecosystem services may be categorized into provisioning (food, freshwater, wood, fuels etc), regulating (climate, flood and disease regulation, water purification etc.) and cultural services (aesthetic, spiritual, educational, recreational etc.). Several of the values from these services are part of the market economy, and hence exposed to negative externalities. Between these categories are trade-offs, interactions and multiple interdependencies.

Kettunen presented the TEEB initiative - The Economics of Ecosystems and Biodiversity. This is one of many important project, along with e.g. the activities within the Nordic Council of Ministers - working with making the ecosystem services values visible.

There are about 300 programmes globally for payment for ecosystem services, covering both the public and the private sector, and the use of such instruments is expanding. Global markets of organic food and drinks and ecotourism are increasing. As an example of economic value of ecosystem, Kettunen referred to the value of EUR 15 billion of pollination by animals.

Kettunen pointed to the importance of improving the foundations, getting the market signals right and encouraging to invest green. She proposed four main points to integrate green economy:

- Understand the value of nature and natural capital even when the values are not market based. 
- Integrate the value of nature and natural capital into the foundations of decisionmaking, such as plans and regulations, accounting systems and impact assessments.

- Provide the right economic signals - remove harmful subsidies and create incentives to sustainable use of natural capital.

- Invest in green activities and create green jobs.

To understand the value of ecosystems, both stocks and flows of ecosystem services must be mapped. Second, the qualitative, quantitative, and monetary values of ecosystem services must be valued. Finally, there is a need to map the status and trends in biodiversity.

\subsubsection{Europe 2020 and the Roadmap for Resource Efficiency}

H.E. Ambassador Janos Herman, Head of the Delegation of the European Union to Norway presented the Europe 2020 Roadmap for Resource Efficiency (see also section 1.2). This is part of the Europe 2020 Strategy, an overall strategy for smart, inclusive and sustainable growth, setting specific goals for employment, $R \& D /$ innovation, climate change/energy, education and poverty/social exclusion. The resource efficiency flagship initiative establishes resource efficiency as the guiding principle for EU policies on energy, transport, climate change, industry, commodities, agriculture, fisheries, biodiversity and regional development.

The Resource Efficiency Roadmap, launched in 2011, proposes ways to increase productivity and decouple economic growth from resource use, with milestones for 2020. Core targets to increase resource-efficiency are to

- Get the prices right - major shifts are needed in taxation, gradually diminishing the tax bases on labour and increasing them on pollution and resource use.

- Get rid of subsidies for inefficient consumption - reduce environmentally damaging subsidies, instead of first subsidising the bads and then repairing the damages.

- Encourage companies to develop sustainable products and services.

- Focus on housing, transport and food.

\subsubsection{The Nordic Task Force on Green growth}

Øyvind Lone, Norwegian Ministry of Environment, presented the Nordic Prime Ministers' Task Force on Green Growth. The remit for the group is to identify Nordic positions of strength and potentials for increased cooperation on green growth, including 2-3 tangible green growth initiatives, 2-3 strategic priorities and opportunities for linking with existing measures and funding sources.

The group presents eight areas for recommendations, and specifies with which ministries are responsible for cooperation. The plan is further outlined in section 1.3.

\subsection{Session 2: Resource efficiency in industry}

This session presented two industrial cases with clear improvements in resource efficiency. The Borregaard case, presented by Kristin Misund, is an example of how 
increasing costs spur innovation to more resource efficient products. The same applies for the Kalundborg case, presented by Niels Larsen.

\subsubsection{Forest industry resource efficiency: Borregaard industries}

Kristin Misund, Borregaard, presented the programs for bio-refinery innovation in Borregaard. Bio-refinery represents processing of biomass into a range of marketable products. This includes e.g. food products, construction materials, textiles, and not least ethanol. Ethanol includes bio fuels, which are important alternatives to fossil fuels and oil based products. Borregaard spends close to NOK 100 mill per year on R\&D to develop new products each year, and about 20 percent of the revenues come from new products.

Misund referred to increasing raw material, energy and labour costs as drivers for innovation. While both technologies and capital were foreign based at the time the company was established, Borregaard is now on the competitive edge on technology, market and innovation competence.

\subsubsection{Resource efficiency and industrial ecology in Kalundborg}

Niels Larsen, Kalundborg Symbiosis, presented the Kalundborg Symbiosis project. This project is an example of an industrial exchange of resources, where one partner's biproduct is the raw material in another partner's production. The project has developed over time, starting with three partners in 1961. Today, more than 30 waste streams exist between partners, and includes water recycling projects, exchange of energy and recycling of waste products. The project contributes to lower use of resources and reduced $\mathrm{CO}_{2}$ emissions.

Larsen claimed that several aspects were important to the development of the Kalundborg project; industrial potentials, economic incentives, no legal barriers and good communication. Despite economic incentives, Larsen claimed that to promote such symbiosis projects in the future, support from the authorities will be important.

\subsection{Session 3: Environmental policy, innovation and technology}

This session focussed on innovation. The first three presentations were based on general research programs - Dirk Pilat the OECD green growth initiative and Rolf Annerberg presented the Nordic Top-level Research Initiative - and Karsten Skov presented a general study of environmental technologies in the Nordic countries. These presentations focussed on correct relative prices as important incentives for innovation. However, stronger means are needed to promote the necessary innovation fast enough, including a mixture of incentives and support to relevant research. Research should be multi- and interdisciplinary with interactions between science and industry in order to gain new innovation insight from scientific interaction.

After innovation, it can be necessary to follow up in the adaptation and implementation of new technologies. The last section focussed on "soft" instruments - green procurement, labelling and voluntary agreements - as means of stimulating adaptation. An important message from Bjørn Bauer is that data is scarce and there is little evidence of the effects of these instruments. 


\subsubsection{Green growth and innovation}

Dirk Pilat, OECD, talked about the role of innovation in green growth. He emphasised water scarcity, climate change, health impacts and biodiversity loss as the main environmental challenges. OECD's green growth framework deals with enabling political conditions for sound environmental development, promoting the transition to more sustainable economies, and measuring different core aspects of green growth.

One of his main messages was that we need lots of innovation, since challenges are so big that we can't afford expensive solutions. Green innovation is mainly driven by relative prices, policy measures and public R\&D. Also, policy stability and flexibility and clear important signals are important. E.g., after the Kyoto Protocol, the patenting activities for renewable energy projects increased markedly. Pilat argued that it is important to support a mix of incentives. He mentioned several examples of positive effects from emission taxes, and also argued that regulation and standards are important policy instruments.

He claimed that there is a need for greater investment in relevant research, which can re-orientate R\&D spending, with focus on both short- and long-term challenges. Research should increasingly be multi- and interdisciplinary with interactions between science and industry. It is important to spread the risk by supporting a range of technologies

\subsubsection{The Nordic Top-level Research Initiative and Green Growth}

Rolf Annerberg, Top-level Research Initiative, presented the Nordic Top-level Research Initiative and Green Growth (TRI), initiated by the Prime Ministers to constitute a coordinated Nordic effort in research and innovation, to find solution to the global challenges of climate, energy and environment. The research questions being addressed are 1) effect studies and adaptation to climate change, 2) interaction between climate change and the cryosphere, 3) energy efficiency with nanotechnology, 4) integration of large-scale wind power, 5) sustainable bio-fuels, and 6) $\mathrm{CO}_{2}$ capture and storage. The project is financed by the Nordic countries and runs over five years. So far, six Nordic Centres of Excellence on climate change and a Nordic Competence centre for CCS research are established, in addition to ten $R \& D$ projects on energy issues and several extensive networks in climate and energy.

The TRI works together with the Nordic Council of Ministers on education, training and research for green growth. Important experiences from the project show that interdisciplinary approach makes it easier to define the problems. The project made policy to action within only two years. Annerberg claimed that the TRI has created a new platform for Nordic cooperation on climate, energy and the environment, with potential for continuation. All the thematic programmes include activities relevant to green growth.

\subsubsection{Environmental technology challenges for the Nordic countries}

Karsten Skov, consultant, presented the project on environmental technologies in the Nordic countries (see also section 2.10). He recommends several actions to promote green growth; improve demand side activities, secure sufficient manpower resources and amounts of funding, more evaluations and clarification of concepts, strong 
leadership and efficient coordination, to improve international cooperation, promote concrete strategies for green growth, and to improve statistics and knowledge. See also section 2.10 .

\subsubsection{Green procurement, labelling and voluntary agreements}

Bjørn Bauer, PlanMiljø, discussed more effective use of green public procurement, green labelling and voluntary agreements (see also section 2.5 and 2.6). He claimed that command and control instruments are not sufficient instruments to promote sustainable production, and that we need sustainable consumption as a vehicle for sustainable production. To work with innovative green public procurement, vision, leadership, strategy, competent and motivated staff is all important prerequisites, in addition to clear structure, systems and culture. While traditional green public procurement is important to promote eco-friendly products, it is insufficient to drive innovation.

Eco-labels are necessary for good information, and could be linked to public procurements. But when comes to soft regulatory instruments, there is little data, few evaluations and little evidence of their effects. This applies also to voluntary agreements. To use voluntary agreements as a growth factor, common guidelines at national level are needed. Research and innovation should be connected, and Bauer recommends policy mixes. For more information on these projects, see also section 2.5 and 2.6.

\subsection{Session 4: Where do we go from here?}

In the last section, Haakon Vennemo discussed the Nordic experiences in light of the environmental policy development in China.

\subsubsection{Green growth: China and the Nordic countries}

Haakon Vennemo, Vista Analysis, discussed green growth in China, and what the Nordic countries can learn from their experiences. China is an important contributor and future driver for greenhouse gas emissions, constituting half of global coal consumption. As a response to high growth in energy demand, China emphasises investments in renewable energy, facing higher growth in wind power and solar energy investments than EU and USA. The rapid growth raises the need for new infrastructure, which to large degree is based on non-fossil fuels. Railway construction and the metro system are prioritized, and 5 mill electric vehicles are planned by 2020.

This is made possible due to state owned enterprises, who obtain cheap credit, local government funding and low return on equity. Funding is devoted to research and development, and public procurement is extensive. In addition to direct funding, prices and tariffs are used as instruments, along with command-and-control instruments and career incentives.

Vennemo concluded that the instruments used are no big secrets - China uses the same tools as we have found efficient - public investment, research and development, green procurement and prices and tariffs. 


\subsection{Panel debate: Green economic growth in the Nordic countries?}

Rolf Annerberg (TRI), Annegrete Bruvoll (Vista Analysis), Magnus Cederlöf (MoE, Finland), Stefan Nordin (Swedish Agency for Economic and Regional Growth)

The subject of the panel debate was how to promote environmental technology, resource efficiency and green economic growth in the Nordic countries. All the panel's participants emphasised the use of marked based tools as instruments for attaining green growth. Removal of environmentally harmful subsidies and getting the prices right are the main tools to promote efficient incentives for lower environmental pressure and improved resource use. Also, support of R\&D and securing information are important to make the markets work in the green direction and to promote a decoupling between the economy and pollution. Happiness research - the potential of decoupling welfare growth from economic growth - was suggested as an important topic for future research.

It was given attention to the risk of using subsidies to support green technologies, as this could give wrong signals to the market regarding the viability of technologies. Also, subsidies may run the risk of stimulating negative side effects, implying environmentally harmful subsidies. The phase out of environmentally harmful subsidies was promoted as part of getting the prices right. 


\section{Concluding words from the summary conference}

In the final section of the conference referred in chapter 4, Hæge Andenæs, Director General, International Cooperation, Norwegian Ministry of Environment, summed up Nordic green initiatives. Andenæs concluded that the Nordic countries' experience shows that it is possible to combine healthy economic growth with ambitious and successful environmental goals and policies. The most effective policies have often been based on combinations of instruments.

The present economic crisis may be an opportunity to a green fiscal consolidation, with reduction and reform of environmentally harmful subsidies and increased revenues from environmental taxes and charges.

Green innovation and technology requires active policies on both the supply side on research and development and on the demand side, along with combined, concerted and coherent action by many sectors and policies. Environmental regulations, standards, prices and taxes are crucial, and green public procurement, voluntary agreements and environmental labelling seem to have considerable unused potential.

Andenæs claimed that the focus on resource efficiency and decoupling of material consumption from economic growth means that waste policy becomes even more important, and it is necessary to aim for "greening" of all sectors.

She refereed to several follow-up initiatives, among them this summary report, input to the Rio2012 in June and the EU2020 "Roadmap on a Resource Efficient Europe", along with several workshops, meetings between all ministers in October 2012 and project proposals on waste, green public procurement, and the eight issues in the Task Force report. 


\section{References}

Barton, D. N., H. Lindhjem, K. Magnussen and S. Holen (2012): Valuation of Ecosystem Services from Nordic Watersheds - from awareness raising to policy support? Nordic Council of Ministers TemaNord 506.

Bauer, B. and R. Fischer-Bogason (2011): Voluntary Agreements and Environmental Labelling in the Nordic Countries, Nordic Council of Ministers TemaNord 538.

Bauer, B., J. Christensen, K. Christensen, T. Dyekjær-Hansen and I. Bode (2009): Benefits of Green Public Procurement, Nordic Council of Ministers TemaNord 593.

Berghäll, E and A. Perrels (2010): The economic crisis and its consequences for the environment and environmental policy, Nordic Council of Ministers TemaNord 555.

Bruvoll, A., K. Ibenholt, S. Ahvenharju, M. Bröckl, L. Martinsen and M. Zandersen (2012): Measuring green jobs? An evaluation of definitions and statistics for green activities, Nordic Council of Ministers TemaNord 534.

Bruvoll, A, J. M. Skjelvik and H. Vennemo (2011): Reforming environmentally harmful subsidies. How to counteract distributional impacts, Nordic Council of Ministers TemaNord 551.

EU (2011): Roadmap to a Resource Efficient Europe, Communication from the commission to the European Parliament, the council, the European economic and social committee and the Committee of the regions, Brussels 20.09.2011.

Hass, J. and V. Palm (2012): Using the right environmental indicators: Tracking progress, raising awareness and supporting analysis. Nordic perspectives on indicators, statistics and accounts for managing the environment and the pressures from economic activities, Nordic Council of Ministers TemaNord 535.

Nordic Council of Ministers (2008): Environment action plan 2009-2012, Copenhagen 2008.

Skjelvik, J. M., A. Bruvoll and K. Ibenholt (2011): Greening the economy: Nordic experiences and challenges, Nordic Council of Ministers TemaNord 532.

Skov, K. (2012): Miljøeffektiv teknologi eller miljøteknologi i de nordiske lande. En undersøgelse af de nordiske landes aktiviteter på området i årene 2004-2011, Nordic Council of Ministers TemaNord 517.

The Nordic prime ministers' Working Group for Green Growth (2011): The Nordic Region - leading in green growth, Nordic Council of Ministers, Copenhagen 2011.

Zandersen, M., K. Grønvik Bråten and H. Lindhjem (2009): Payment for and Management of Ecosystem Services, Nordic Council of Ministers TemaNord 571. 



\section{Vista Analysis AS}

Vista Analysis is a social science consultancy with its main emphasis on economic research, policy analysis and advice, and evaluations. We carry out projects to the highest professional standards, with independence and integrity. Our key thematic areas include climate change, energy, transport, urban planning and welfare issues.

Our employees have high academic credentials and broad experience within consulting. When needed we utilise an extensive network of companies and resource persons nationally and internationally. The company is fully employee-owned.

\section{Vista Analysis AS}

Meltzersgate 4

0257 Oslo

post@vista-analyse.no

vista-analyse.no 